\title{
Diflunisal in osteoarthrosis of the hip and knee
}

\author{
W. K. ESSIGMAN, ${ }^{1}$ M. ANNE CHAMBERLAIN, ${ }^{2}$ AND V. WRIGHT ${ }^{3}$ \\ From the ${ }^{1}$ Lister Hospital, Stevenage, Hertfordshire, the ${ }^{2}$ General Infirmary, Leeds, and the \\ ${ }^{3}$ University of Leeds
}

SUMMARY Diflunisal (750 mg per day) has been compared with acetylsalicylic acid (ASA) (3000 mg per day) in the treatment of osteoarthrosis of the hip and knee in a double-blind, randomise multicentre, outpatient study. Thirty-one patients entered the diflunisal group and 29 the ASA grougi The response of the 2 groups was comparable, but the incidence of side effects was higher in the ASA group. At the end of the 12-week period more patients in the diflunisal group chose to remaid in a further, open study.

A wide variety of non-steroidal anti-inflammatory drugs is now available for use in the treatment of chronic arthropathies. It is useful to compare the efficacy of a new compound with a well established therapy. In the present study, diflunisal, a new aspirin derivative, has been assessed against acetylsalicylic acid.

\section{Pharmacology}

Diflunisal, or difluoro-phenylsalicylic acid, has been shown to be superior to placebo in the treatment of pain (de Vroey, 1978; Honig, 1978; Wes, 1978) and to possess both analgesic (van Winzum and Rodda, 1977; Barrau, 1978; de Vroey, 1978; Honig, 1978; Wes, 1978) and anti-inflammatory properties (Majerus and Stanford, 1977; Stone et al., 1977). It is well absorbed from the gastrointestinal tract, and most of it is bound in its intact form to plasma protein. The peak plasma levels occur approximately 2 hours after oral administration of $50 \mathrm{mg}$ and 500 $\mathrm{mg}$ of the drug. The half-life of the $500 \mathrm{mg}$ dose is about 10 hours. The presence of food in the stomach does not significantly delay absorption. 80-85\% of $500 \mathrm{mg}$ dose of diflunisal is eliminated in the urine in the form of glucoronide metabolites. A small proportion of metabolite appear in the faeces. In animal experiments no interaction was observed between diflunisal and bishydroxycoumarin in the prothrombin test nor with tolbutamide in the glucose tolerance test.

Accepted for publication 2 June 1978

Correspondence to Dr M. Anne Chamberlain, Rheumatism Research Unit, School of Medicine, 36 Clarendon Road, Leeds LS2 9PJ.

\section{Patients and methods}

Sixty patients between the ages of 35 and 75 yeans were admitted to the trial. Twelve were male and 48 were female. Twenty-four patients suffered fro osteoarthrosis of the hip and 36 from osteoarthrosts of the knee. The obligatory criteria for admission to the study were local pain aggravated by movememt and relieved by rest, limitation of movement in the affected joint, and characteristic radiological changes. The additional criteria considered were night pain and the presence of inactivity stiffness.

Patients with a history of gastrointestinal disease (including definite peptic ulceration within the last 2 years or haemorrhage at any time), renal arid cardiovascular disease, other joint diseases (such rheumatoid arthritis), serious systemic illnesses sue as diabetes mellitus, active tuberculosis, and marro depression, and women of child-bearing potential were excluded.

Patients currently receiving anticoagulants, or hypoglycaemic agents, digitoxin, and systemic steroid therapy, as well as those who had previous $\$$ demonstrated hypersensitivity to salicylates, we also excluded.

\section{ST UDY DESIGN}

The trial was a double-blind study comparing tt度 respective efficacy and safety of diflunisal givên twice a day (max. $750 \mathrm{mg} /$ day) and acetylsalicylio acid (max. $3 \mathrm{~g} /$ day) given 4 times a day over a cour of 12 weeks. Patients were allocated by a rando\$ allocation schedule to each of the therapies, that acetylsalicylic acid (ASA) or diflunisal. Each patie received two bottles, each containing tablets of 
different appearance and labelled $\mathbf{A}$ and $\mathbf{B}$ so that, with placebos at suitable times, each patient apparently received therapy 4 times daily. If pain was not relieved at the end of the first or second treatment week, the dose was increased from 2 to 4 tablets 4 times daily and maintained for the rest of the trial.

All anti-inflammatory drugs were withdrawn during the 7-day pretreatment period and not allowed for the duration of the study. Physiotherapy was not allowed either.

A full medical examination, electrocardiogram, and examination of the eyes by an ophthalmologist were performed before the patients were admitted to the study and at the end of the 12-week period. Clinical assessment and laboratory tests, which included full blood count, blood urea, serum urate, liver function tests, and examination of urine, were carried out weekly in the initial stages of the trial and then at monthly intervals.

\section{CLINICAL ASSESSMENT}

Weight bearing pain, night pain, and pain suffered during performance of a specific functional activity such as getting in and out of bed, getting up from a chair, walking a stated distance, or climbing stairs were graded by the patients on a scale ranging from $0=$ none to $4=$ very severe. Inactivity stiffness was measured in minutes. Patients were also asked to evaluate their overall response to treatment, and the investigator to assess the therapeutic effect, again using the 0-4 scale. The degree of flexion of the knee in osteoarthrosis of the knee and the intramalleolar distance in osteoarthrosis of the hip were used by the investigator in evaluation of the limitation of movement. At each visit inquiry was made as to the appearance of new symptoms that could have been attributed to the drugs used in the trial.

\section{Results}

The groups were well matched immediately prior to entry as regards the degree of weight bearing pain, night pain, and pain suffered during a specific functional activity (Table 1).
Of the 31 patients in the diflunisal group 24 completed the 12-week study compared with 14 out of 29 in the ASA group. Improvement was considered to have occurred if there was a decrease on the $0-4$ pain scale, a $10 \%$ improvement in the measurements taken for limitation of movement, and a $10 \%$ decrease in the inactivity stiffness time. The final assessment at the end of the 12-week period showed that a considerable proportion of the patients in both groups experienced an improvement in all of the clinical parameters of at least 1 grade, except for the limitation of movement (Table 2). There was no statistical difference in the response to treatment between the 2 groups (Fisher's exact test).

The patients' overall opinion of response and the investigator's assessment of therapeutic effect at the end of the 12-week period did not differ significantly between the 2 groups as shown in Table 3 .

Table 2 Percentage of patients who showed improvement in the clinical parameters after 12 weeks

\begin{tabular}{lll}
\hline Variables & \multicolumn{2}{l}{$\%$ patients improved } \\
\cline { 2 - 3 } & Diflunisal & Aspirin \\
\hline Weight bearing pain & 71 & 64 \\
Night pain & 54 & 79 \\
Functional activity & 75 & 71 \\
Inactivity stiffness & 75 & 50 \\
Range of movement & 42 & 43 \\
\hline
\end{tabular}

Table 3 Number of patients with each rating for clinician and patient overall assessment after 12 weeks

\begin{tabular}{llll}
\hline Groups & Rating & $\begin{array}{l}\text { Investigator } \\
\text { assessment }\end{array}$ & $\begin{array}{l}\text { Patient } \\
\text { assessment }\end{array}$ \\
\hline Diflunisal & 0 =none & 3 & 3 \\
& 1 = poor & 4 & 1 \\
2 = fair & 5 & 6 \\
& $3=$ good & 5 & 6 \\
Aspirin & 4 =excellent & 7 & 8 \\
& 0 =none & 3 & 1 \\
& 1 = poor & 2 & 3 \\
& 2 =fair & 2 & 2 \\
& $3=$ good & 3 & 3 \\
& $4=$ excellent & 4 & 5 \\
\hline
\end{tabular}

Table 1 Number of patients with each rating for subjective assessment prior to entry

\begin{tabular}{|c|c|c|c|c|c|c|}
\hline \multirow{2}{*}{$\begin{array}{l}\text { Rating } \\
\text { (Scale 0-4) }\end{array}$} & \multicolumn{2}{|c|}{ Weight bearing pain } & \multicolumn{2}{|l|}{ Night pain } & \multicolumn{2}{|c|}{ Function activity pain } \\
\hline & Diflunisal & Aspirin & Diflunisal & Aspirin & Diflunisal & Aspirin* \\
\hline $\begin{array}{l}0 \\
1 \\
2 \\
3 \\
4\end{array}$ & $\begin{array}{r}1 \\
3 \\
10 \\
12 \\
5\end{array}$ & $\begin{array}{r}0 \\
3 \\
9 \\
14 \\
3\end{array}$ & $\begin{array}{r}7 \\
10 \\
9 \\
4 \\
1\end{array}$ & $\begin{array}{r}6 \\
11 \\
8 \\
3 \\
1\end{array}$ & $\begin{array}{r}0 \\
5 \\
14 \\
10 \\
2\end{array}$ & $\begin{array}{r}1 \\
2 \\
15 \\
7 \\
3\end{array}$ \\
\hline
\end{tabular}

*1 patient was not assessed. 


\section{WITHDRAWALS AND SIDE EFFECTS}

Side effects were the main reasons for withdrawals in both groups, but the incidence, both in patients completing the trial and in those who were withdrawn, was higher in the ASA group, although this difference was not statistically significant Table 4 .

In patients taking diflunisal the side effects which resulted in withdrawal were indigestion (1), diarrhoea (1), constipation (1), and hallucinations (1). The patient who developed hallucinations had been on concomitant nitrazepam therapy. Symptoms were severe and disturbing, but subsided completely within 24 hours of discontinuing the diflunisal. It is interesting to note that another patient who had been taking nitrazepam simultaneously with diflunisal developed lethargy and drowsiness. This lasted a couple of days but improved spontaneously without alteration to therapy.

The side effects in the diflunisal group, both in patients who completed the trial and in those who had to be withdrawn, were predominantly gastrointestinal, namely, indigestion (5) (although only 1 was withdrawn from the trial for this reason), nausea (2), flatulence (1), diarrhoea (1), and constipation (1). In 1 patient the platelet count dropped to 90000 as recorded at week 12 . A week later the count was still low at 92000 , and the drug was discontinued. However, full recovery followed within 2 weeks. There was no change in any other laboratory measured parameters except for a significant fall in serum uric acid. This confirmed the original findings of Tempero et al. (1976) (Table 5).

Similarly in the ASA group the side effects were also mainly gastrointestinal, namely, indigestion (8), though only 2 were withdrawn from the trial because of this, nausea (5), diarrhoea (2), constipation (1), rash on face (1), and ankle swelling (1). In 1 patient there was a rise in blood urea and AST. Other adverse laboratory findings were raised serum uric acid in 1 patient and increased excretion of white blood cells in the urine of another.

\section{Discussion}

Acetylsalicylic acid was known as a herbal remedy to

Table 4 Numbers of patients withdrawn during the study and incidence of adverse reactions

\begin{tabular}{lrrl}
\hline & Diflunisal & Aspirin & $\begin{array}{l}P \text { value } \\
\text { (2-tailed) }\end{array}$ \\
\hline Total entry & 31 & 29 & \\
Unrelated withdrawals & 1 & 5 & $\mathbf{P}>0 \cdot 1$ \\
Related withdrawals (\%) & $6(20)$ & $10(34)$ & $\mathbf{P}>0 \cdot 1$ \\
$\quad$ Lack of response & 2 & 0 & $\mathbf{P}>0 \cdot 1$ \\
$\quad$ Side effects & 4 & 9 & $0.05<\mathbf{P}<0 \cdot 1$ \\
$\quad$ Adverse Lab. & 0 & 1 & $\mathbf{P}>0 \cdot 1$ \\
Adverse reactions (\%) & $13(42)$ & $21(72)$ & $0.05<P<0.1$ \\
(lab. and side effects) & & & \\
\hline
\end{tabular}

Table 5 Diflunisal group-Laboratory tests

\begin{tabular}{|c|c|c|c|c|}
\hline & & $\begin{array}{l}\text { Start of } \\
\text { trial } \\
(\text { week } 0)\end{array}$ & $\begin{array}{l}\text { End of } \\
\text { trial } \\
\text { (week 12) }\end{array}$ & Significance \\
\hline Haemoglobin & mean & $14 \cdot 4$ & $15 \cdot 9$ & \\
\hline Male & SD & $1 \cdot 88$ & $1 \cdot 94$ & NS \\
\hline Haemoglobin & mean & $13 \cdot 6$ & $14 \cdot 2$ & \\
\hline Female & SD & 0.98 & 0.97 & NS \\
\hline Haematocrit & mean & $40 \cdot 4$ & $42 \cdot 1$ & \\
\hline & SD & $3 \cdot 78$ & $3 \cdot 89$ & NS \\
\hline Leucocytes & mean & $7 \cdot 2$ & $7 \cdot 0$ & \\
\hline & SD & $2 \cdot 08$ & $2 \cdot 21$ & NS \\
\hline Platelets & mean & 190000 & 205000 & NS \\
\hline & SD & 81 & 62 & \\
\hline Creatinine & mean & $84 \cdot 0$ & $91 \cdot 2$ & \\
\hline & SD & $8 \cdot 31$ & $8 \cdot 26$ & NS \\
\hline Blood urea & mean & $5 \cdot 6$ & $6 \cdot 4$ & \\
\hline & SD & $1 \cdot 27$ & $1 \cdot 32$ & NS \\
\hline Uric acid & mean & 0.31 & $0 \cdot 23$ & $\mathrm{P}<\cdot 001$ \\
\hline & SD & 0.062 & 0.065 & $(t$ test $)$ \\
\hline Bilirubin & mean & $12 \cdot 3$ & $11 \cdot 4$ & \\
\hline & SD & $3 \cdot 17$ & $4 \cdot 96$ & NS \\
\hline Alk. Phos. & mean & $169 \cdot 6$ & $160 \cdot 4$ & \\
\hline & SD & $53 \cdot 3$ & $36 \cdot 6$ & NS \\
\hline AST & mean & $16 \cdot 0$ & $14 \cdot 73$ & \\
\hline & SD & 3.96 & $4 \cdot 22$ & NS \\
\hline Urine & & \multicolumn{3}{|c|}{ No abnormality } \\
\hline
\end{tabular}

SD $=$ Standard deviation $. \quad N S=$ Not significant.

Hippocrates, who recognised the therapeutic pros perties of the willow tree bark, and has been proves over the years to be a drug of unquestionable analgesic and anti-inflammatory actions. In ito various forms it is still used extensively in the treat ment of many rheumatic disorders and othes painful conditions, although the incidence of side effects is often high and a proportion of patien cannot tolerate the drug.

The aspirin used in this study was formulated i either film coated tablets (visually identical to placeboid or in peach coloured capsules identical to diflunisa?. so that patients took apparently identical dose schedules. For convenience in the preparation o\& these tablets $250 \mathrm{mg}$ aspirin was incorporated into each.

Diflunisal was thus compared with the basie traditional therapy, aspirin, for its analgesic property. safety, and acceptability. Twelve weeks was con sidered long enough for the placebo effect of a nets therapy to have declined markedly.

The 2 drugs were of comparable efficacy in relieving pain, stiffness, and immobility. Howeveb side effects were less frequent with diflunisal thaf with aspirin and were less disturbing. All withdrawals related to drug administration in the acetylsalicylie group were due to side effects, of which there were more with aspirin than with diflunisal.

No serious side effects were encountered wit diflunisal. It should be noted, however, that patients taking nitrazepam at the same time, 
developed symptoms suggestive of central nervous system disturbance. Nitrazepam itself is known to produce unpleasant dreams and hallucinations in some patients, but the number in this trial is too small to suggest any definite conclusions as to the synergistic effect which may occur between these 2 drugs. A transient fall in platelets count was encountered in 1 patient, but recovery was spontaneous and full when the drug was discontinued.

At the end of the double-blind 12-week study more patients taking diflunisal (21) than acetylsalicylic acid (8) chose to remain in the open study. We hope to present the results of this study in a further communication.

This trial showed that diflunisal is a useful drug in the treatment of osteoarthrosis of the hip and knee. The incidence of side effects is acceptable and twice daily dosage is a definite advantage (Wright and Hopkins, 1976).

We acknowledge with pleasure the help of the following: Mrs P. Leatham, our research nurse, Mrs J. Packter for secretarial help, Mr C. Hetherington of the General Infirmary at Leeds and their Pharmaceutical Department, Mrs D. Burdon, Dr A. Rhymer, Dr R. Roylance, and Dr B. Boeree of Merck, Sharpe and Dohme.

\section{References}

Barrau, G. (1978). Double-blind comparison of the efficacy and tolerance of diflunisal and oxyphenbutazone in the treatment of sprain and strain. Clinical Therapeutics, 1, Suppl. A, 43-48.

De Vroey, P. (1978). The treatment of postoperative pain with a single dose of difiunisal. Clinical Therapeutics, 1, Suppl. A, 30-33.

Honig, W. J. (1978). The use of diflunisal following meniscectomy. Diflunisal in Clinical Practice, p. 105. Edited by K. Kiehlke. Futura Press.

Majerus, P. W., and Stanford, N. (1977). Comparative effects of aspirin and diflunisal on prostaglandin synthetase from human platelets and sheep seminal vesicles. British Journal of Clinical Pharmacology, 4, 15S-18S.

Stone, C. A., van Arman, C. G., Lotti, V. J., Minsker, D. H., Risley, E. A., Bagdon, W. J., Bokelman, D. L., Jensen, R. D., Mendlowski, B., Tate, C. L., Peck, H. M., Zwickey, R. E., and McKinney, S. E. (1977). Pharmacology and toxicology of diflunisal. British Journal of Clinical Pharmacology, 4, 19S-29S.

Tempero, K. F., Franklin, J., Reger, B., and Kappas, A. (1976). The influence of diflunisal, a novel analgesic on serum uric acid and uric acid clearance. Clinical Research, 24, 258A.

Van Winzum, C., and Rodda, B. (1977). Diflunisal efficacy in postoperative pain. British Journal of Clinical Pharmacology, 4, 39S-43S.

Wes, B. J. (1978). Diflunisal in oral surgery. Clinical Therapeutics, 1, Suppl. A, 34-42.

Wright, V., and Hopkins, R. (1976). Administration of antirheumatic drugs. Annals of the Rheumatic Diseases, 35, 174-176. 